\title{
Deficit in Complement C4 Fraction Associated with Autoimmune Manifestations and Vertebral Osteolytic Lesions
}

\author{
K Chaanoun*, H Benjelloun, N Zaghba, N Yassine
}

Department of Respiratory Disease, Chu Ibn Rochd, 1, Rue des Hôpitaux, Casablanca, Morocco

DOI: $10.36347 /$ simcr.2020.v08i07.020

| Received: 10.07.2020 | Accepted: 18.07.2020 | Published: 28.07.2020

*Corresponding author: K Chaanoun

Abstract

The C4 protein is part of the classical complement pathway which plays an important role in innate immunity and in the maintenance of immune complexes in the soluble phase. We report the observation of a 35 year old patient admitted to the respiratory diseases department for etiological assessment of diffuse bronchial dilatation foci (DDB) complicating repeated respiratory infections. After eliminating an acquired immunodeficiency, a balance of primary immune deficiency carried out, allowing to retain the diagnosis of a deficit in complement fraction $\mathrm{C} 4$ associated with a systemic lupus erythematosus. Complete C4 deficiency is very rare, can be revealed in adulthood by bacterial infections with encapsulated germs and predisposes to diseases with deposits of immune complexes. Requiring a diagnosis and an early management in order to avoid complications sometimes frightening, as was the case of our patient.

Keywords: C4 protein, immunity, (DDB), infections.

Copyright @ 2020: This is an open-access article distributed under the terms of the Creative Commons Attribution license which permits unrestricted use, distribution, and reproduction in any medium for non-commercial use (NonCommercial, or CC-BY-NC) provided the original author and source are credited.

\section{INTRODUCTION}

The complement system is a set of proteins synthesized in the liver in an inactive form, most of which have an enzymatic activity. It is involved both in the fight against infections, in particular in bacteria encapsulated via the membrane attack complex, the elimination of immune complexes and also in the modulation of specific immune response. It also has non-immune functions such as lipid metabolism, maturation of synapses and blood clotting [1]. Complement protein $\mathrm{C} 4$ is an essential component of the classical pathway that is initiated by attachment of the $\mathrm{C} 1$ complex to immunoglobulins. This complex will be able to cleave $\mathrm{C} 4$ and $\mathrm{C} 2$ to form the classic $\mathrm{C} 3$ convertase (C4b2a) essential for the formation of the membrane attack complex.

\section{ObSeRVATION}

$\mathrm{Mr}$ K.W aged 35, from a 1st degree consanguineous marriage. Having as a family history, two sisters who died one at the age of 21 by meningoencephalitis and the other at the age of 39 in an acute respiratory failure table following a bacterial superinfection of foci of dilation of the bronchi. Our patient presented since the age of 11 years with recurrent bronchopneumonia complicated by foci of dilation of the bronchi. Followed from the age of 17 years for an autoimmune hemolytic anemia splenectomized after failure of corticotherapy, had presented an abscessed appendicular chest plate 14 years ago, a pulmonary tuberculosis probable 13 years ago, a pneumococcal meningitis 11 years ago and who had alopecia plaques for 10 years. Admitted to the respiratory diseases department for a bacterial superinfection of foci of dilation of the diffuse bronchi. The clinical examination at admission found moderate digital hippocratism and toes, cervical hyperlordosis and dorsal kyphosis. Chest imaging had shown focal areas of bilateral cylindrical bronchi with associated mediastinal lymphadenopathy and lyric vertebral lesions of suspicious appearance with a nibbled appearance of the cervico-dorsal vertebrae and compacted pancake of the D5.

After treating the episode of bacterial superinfection of DDB foci. An assessment made to eliminate a malignant origin of vertebral lesions, in particular multiple myeloma or bone metastases from thyroid or renal cancer was negative. CT of the spine showed confluent osteolytic lesions of the vertebral bodies from D2 to D9 with peripheral osteosclerosis and wedge packing of D5. A bone biopsy was proposed but not done due to the absence of active vertebral lesions detectable on MRI. Regarding the etiological assessment of DDB foci, a serology of the human 
immunodeficiency virus (HIV) was negative, a sweat test and an alpha1 antitrypsin test were normal. Also an electrophoresis of plasma proteins, a weight assay of serum immunoglobulins (IgG, IgM, IgA and the IgG subclasses) and a lymphocyte phenotyping were without particularity.

However, the activity of the total hemolytic complements $(\mathrm{CH} 50)$ as well as the rate of the $\mathrm{C} 4$ fraction were collapsed. In contrast, the level of the other fractions of the complement $\mathrm{C} 2, \mathrm{C} 3, \mathrm{C} 5, \mathrm{C} 7, \mathrm{C} 8$ and C9 was normal.Bronchoscopy showed a diffuse inflammatory state with thickening of the spurs, bronchial biopsies done in favor of an inflammatory change.In addition, the blood count showed a normochromic macrocytic anemia. The Haptoglobin level was collapsed, the LDH level was normal and the Coombs test was positive (Ig G C3d). To eliminate cryoglobulinemia, the search for cold agglutinins.

As part of the systemic lupus erythematosus assessment, the immunological assessment performed was negative except the anti RNP antibodies were positive.The abdominal ultrasound showed a portal vein thrombosis with the appearance of a portal cavernoma. At the hepatic assessment, there was a slight cytolysis with cholestasis. Viral hepatitis B and C serologies were negative. Digestive fibroscopy found an aspect of ulcerative and polyploid duodenitis, biopsies was in favor of nodular lymphoid hyperplasia without signs of malignancy. An immunological assessment in the context of autoimmune As part of the systemic lupus erythematosus assessment, the immunological assessment performed was negative except the anti RNP antibodies were positive.

The abdominal ultrasound showed a portal vein thrombosis with the appearance of a portal cavernoma. At the hepatic assessment, there was a slight cytolysis with cholestasis. Viral hepatitis B and C serologies were negative. Digestive fibroscopy found an aspect of ulcerative and polypoid duodenitis, biopsies were in favor of nodular lymphoid hyperplasia without signs of malignancy. An immunological assessment in the context of autoimmune hepatitis as well as a thrombophilia assessment with a search for circulating anticoagulants was negative. The portal cavernoma is most likely a postoperative complication of splenectomy.

The presence of hemolytic anemia and thrombosis of the portal vein should suggest a paroxysmal nocturnal hemoglobinuria (PNH), an analysis of symmetry of dependent GPI markers (CD14 CD55 CD66b) on monocytes and PNN did not show from clone HPN.For skin lesions, the skin biopsy was in favor of nonspecific scar alopecia. The lip biopsy performed showed a granuloma without caseous necrosis. The diagnosis was made of a deficit in complement $\mathrm{C} 4$ fraction associated with systemic lupus erythematosus according to the diagnostic criteria of ACR with cutaneous and hematological manifestations.

The impact report showed type 1 respiratory failure with severe hypoxia and pulmonary hypertension with a chronic pulmonary heart appearance on cardiac ultrasound.The patient has always been followed up for 4 years, the general condition is still preserved. He is currently on long-term oxygen therapy, diuretics, respiratory physiotherapy, antibiotic prophylaxis and vitamin D supplementation.

\section{DISCUSSION}

The C4 fraction is part of the classical complement route. It is encoded by two genes, $\mathrm{C} 4 \mathrm{~A}$ and $\mathrm{C} 4 \mathrm{~B}$ located in the class III region of the major histocompatibility complex MHC on the short arm of chromosome 6 (MIM +120810 and* 120820, respectively) [3, 4]. The presence of non-functional $\mathrm{C} 4 \mathrm{~A}$ or $\mathrm{C} 4 \mathrm{~B}$ genes is responsible for a complete deficiency in $\mathrm{C} 4 \mathrm{~A}$ or $\mathrm{C} 4 \mathrm{~B}$, called the homozygous $\mathrm{C} 4$ deficiency. The presence of a $\mathrm{C} 4 \mathrm{~A}$ or $\mathrm{C} 4 \mathrm{~B}$ gene is called partial or heterozygous $\mathrm{C} 4 \mathrm{~A}$ or $\mathrm{C} 4 \mathrm{~B}$ deficiency [5].

Complement protein deficits can be acquired or inherited. Acquired deficits are relatively common and can result either from a decrease in protein synthesis, especially in patients followed for hepatic cirrhosis, an excessive loss during a nephrotic syndrome or an increased consumption often linked to a disease. with immune complexes, notably LES and therefore the dosage of complement fractions constitutes a biomarker of disease activity.However, hereditary $\mathrm{C} 4$ deficits are relatively rare. May be partial what is common in the general or a complete population (neither the functional $\mathrm{C} 4 \mathrm{~A}$ nor functional $\mathrm{C} 4 \mathrm{~B}$ genes), the latter remains exceptional and to date only 28 patients have been described in the literature [6-8].

Homozygous C4A and C4B deficiencies differ in their clinical characteristics and their associations with disease. Our patient presented with recurrent respiratory infections complicated by diffuse bronchitis' and autoimmune manifestations. Unfortunately the diagnosis was late in the stage of chronic respiratory failure and chronic pulmonary heart, the interest of an early diagnosis, especially in the presence of a family history of immune deficiencies.

The data in the literature on the predisposition to infections during $\mathrm{C} 4$ deficiency are controversial [22]. A study in Finland has shown that $\mathrm{C} 4$ deficiency is responsible for recurrent respiratory infections in children and adolescents [21] and studies have shown that $\mathrm{C} 4 \mathrm{~B}$ deficiency is associated with an increased risk of infections, in particular with invasive germs [24,9, 22-23]. Also, other studies have demonstrated the association of this deficit with the development of pulmonary tuberculosis [9] and others have shown that 
patients with non-tuberculous mycobacterial pulmonary infections often have a deficiency. in $\mathrm{C} 4$ compared to control subjects [2].

In addition to infectious complications, homozygous $\mathrm{C} 4 \mathrm{~A}$ deficiency is linked to systemic autoimmune diseases characterized by the production of autoantibodies, most often it is systemic lupus erythematosus $[17-20,15,25,26]$. On the other hand, the C4B deficiency does not seem to be more frequent in the patients followed for lupus, but the latter deficit would predispose to insulin-dependent diabetes, coronary artery disease [11] or glomerular disease [12, 13]. Thus other autoimmune manifestations linked to $\mathrm{C} 4$ deficiency have been reported in the literature such as autoimmune rheumatic diseases, celiac disease, Henoch-Schönlein purpura, juvenile idiopathic arthritis and rheumatoid arthritis [5, 7, 9, 14].

The age at onset of symptoms and the severity of the disease vary considerably from one subject to another, probably in relation to other genetic and / or environmental factors that play a role in the development and pathogenesis of the disease.

It is likely to be assumed that in the event of complete or partial C4 deficiency, the infection can contribute to autoimmunity through mechanisms involving molecular mimicry.

C4 deficiency is also associated with other complications such as the development of lymphoma, sarcoidosis or capillary leak syndrome during cardiopulmonary bypass surgery in children. However, the number of cases reported in the literature remains very low $[10,15,16]$.

Our patient had on the lip biopsy, a granuloma without caseous necrosis, bronchial biopsies performed did not find granulomatous lesions. Regarding the bone lesions we could not retain an etiological diagnosis remains most likely of autoimmune origin without being able to confirm this.

\section{CONCLUSiON}

The complete hereditary deficit in $\mathrm{C} 4$ remains exceptional. Repetitive infections, in particular with encapsulated germs, the presence of autoimmune manifestations and a family history of immune deficiency should lead to the search for a primitive immune deficiency, in particular a deficiency in complement.

\section{REFERENCE}

1. Ricklin D, Hajishengallis G, Yang K, Lambris JD. Complement: A key system for immune surveillance and homeostasis. Nat Immunol. 2010;11: 785-797.
2. Hannele K, Marja-Liisa L, Riitta P, , Mikko S, Pentti T, Seppo M. Complement C4 Deficiency A Plausible Risk Factor for Non-Tuberculous Mycobacteria (NTM) Infection in Apparently Immunocompetent Patients. PLoS One. 2014; 9(3): e91450.

3. Yu C, Belt K, Giles C, Campbell R, Porter R. Structural basis of the polymorphism of human complement components $\mathrm{C} 4 \mathrm{~A}$ and $\mathrm{C} 4 \mathrm{~B}$ : Gene size, reactivity and antigenicity. EMBO J. 1986;5: 2873-2881.

4. Dangel AW, Mendoza AR, Menachery CD, Baker BJ, Daniel CM, Carroll MC. The dichotomous size variation of human complement $\mathrm{C} 4$ genes is mediated by a novel family of endogenous retroviruses, which also establishes speciesspecific genomic patterns among old world primates. Immunogenetics. 1994;40: 425-436.

5. Blanchong CA, Zhou B, Rupert KL, Chung EK, Jones KN, Sotos JF. Deficiencies of human complement component $\mathrm{C} 4 \mathrm{~A}$ and $\mathrm{C} 4 \mathrm{~B}$ and heterozygosity in length variants of RP-C4CYP21-TNX (RCCX) modules in caucasians. The load of RCCX genetic diversity on Major Histocompatibility Complex-associated disease. The Journal of experimental medicine. 2000;191: 2183-2196.

6. Lipsker D, Hauptmann G. Cutaneous manifestations of complement deficiencies. Lupus. 2010;19: 1096-1106.

7. $\mathrm{Wu} Y \mathrm{~L}$, Hauptmann $\mathrm{G}$, Viguier $\mathrm{M}, \mathrm{Yu}$ CY. Molecular basis of complete complement C4 deficiency in two North-African families with systemic lupus erythematosus. Genes and immunity. 2009;10: 433-445.

8. Lokki ML, Circolo A, Ahokas P, Rupert KL, Yu $\mathrm{CY}$ and Colten HR. Deficiency of human complement protein $\mathrm{C} 4$ due to identical frameshift mutations in the $\mathrm{C} 4 \mathrm{~A}$ and $\mathrm{C} 4 \mathrm{~B}$ genes. J Immunol. 1999; 162: 3687-3693.

9. Senbagavalli P, Kumar N, Kaur G, Mehra NK, Geetha ST and Ramanathan VD. Major Histocompatibility Complex class III (C2, C4, factor B) and C3 gene variants in patients with pulmonary tuberculosis. Hum Immunol. 2011;72: 173-178.

10. Zhang S, Wang S, Li Q, Yao S, Zeng B, Ziegelstein RC. Capillary leak syndrome in children with C4A-deficiency undergoing cardiac surgery with cardiopulmonary bypass: A doubleblind, randomised controlled study. Lancet. 2005;366: 556-562.

11. Szalai C, Fust G, Duba J, Kramer J, Romics L, Prohászka Z. Association of polymorphisms and allelic combinations in the tumour necrosis factoralpha-complement MHC region with coronary artery disease. J Med Genet. 2002;39: 46-51.

12. 12 Soto K, Wu YL, Ortiz A, Aparicio SR, Yu CY. Familial C4B deficiency and immune 
complex glomerulonephritis. Clin Immunol. 2010;137: 166-175.

13. Mougey R. A review of the Chido/Rodgers blood group. Immunohematology. 2010;26: 30-38.

14. Rittner C, DeMarchi M, Mollenhauer E, Carbonara A. Coeliac disease and $\mathrm{C}_{4} \mathrm{~A}^{*} \mathrm{q} 0$ : $\mathrm{An}$ association secondary to HLA-DR3. Tissue Antigens. 1984;23: 130-134.

15. Wennerstrom A, Pietinalho A, Vauhkonen $\mathrm{H}$, Lahtela L, Palikhe A, Herman J. HLA-DRb1 allele frequencies and $\mathrm{C} 4$ copy number variation in Finnish sarcoidosis patients and associations with disease prognosis. Hum Immunol. 2012;73: 93100.

16. Inka L, Riitta P, Asko J, Ville V, Marja-Liisa L. Clinical features of patients with homozygous complement C4A or C4Bdeficiency. PLoS One. 2018; 13(6): e0199305.

17. Boteva L, Morris DL, Cortes-Hernandez J, Martin J, Vyse TJ, Fernando MM. Genetically determined partial complement $\mathrm{C} 4$ deficiency states are not independent risk factors for sle in UK and Spanish populations. Am J Hum Genet. 2012;90: 445-456.

18. Yang Y, Chung EK, Wu YL, Savelli SL, Nagaraja HN, Zhou B. Gene copy-number variation and associated polymorphisms of complement component $\mathrm{C} 4$ in human systemic lupus erythematosus (SLE): Low copy number is a risk factor for and high copy number is a protective factor against SLE susceptibility in European Americans. Am J Hum Genet. 2007;80: 10371054.

19. Ittiprasert W, Kantachuvesiri S, Pavasuthipaisit K, Verasertniyom O, Chaomthum L, Totemchokchyakarn K, et al. Complete deficiencies of complement $\mathrm{C} 4 \mathrm{~A}$ and $\mathrm{C} 4 \mathrm{~B}$ including 2-bp insertion in codon 1213 are genetic risk factors of systemic lupus erythematosus in thai populations. J Autoimmun. 2005;25: 77-84.
20. Man X, Luo H, Li X, Yau Y, Mao C, Zhang Y. Polymerase chain reaction based $\mathrm{C} 4 \mathrm{Aq} 0$ and C4Bq0 genotyping: Association with systemic lupus erythematosus in southwest Han Chinese. Ann Rheum Dis. 2003;62: 71-73.

21. Kainulainen L, Peltola V, Seppanen M, Viander M, He Q, Lokki ML. C4A deficiency in children and adolescents with recurrent respiratory infections. Hum Immunol. 2012;73: 498-501.

22. Skattum $L$, van Deuren $M$, van der Poll $T$, Truedsson L. Complement deficiency states and associated infections. Mol Immunol. 2011;48: 1643-1655.

23. Rigby WF, Wu YL, Zan M, Zhou B, Rosengren S, Carlson C. Increased frequency of complement C4B deficiency in rheumatoid arthritis. Arthritis Rheum. 2012;64: 1338-1344.

24. Samano ES, Ribeiro Lde M, Gorescu RG, Rocha $\mathrm{KC}$, Grumach AS. Involvement of $\mathrm{C} 4$ allotypes in the pathogenesis of human diseases. Revista do Hospital das Clinicas. 2004;59: 138-144.

25. Lintner KE, Wu YL, Yang Y, Spencer CH, Hauptmann G, Hebert LA, Atkinson JP, Yu CY1. Early Components of the Complement Classical Activation Pathway in Human Systemic Autoimmune Diseases Front Immunol. 2016; 7: 36.

26. Chen JY, Wu YL, Mok MY, Wu YJ, Lintner KE, Wang CM, Chung EK, Yang Y, Zhou B, Wang H, Yu D, Alhomosh A, Jones K, Spencer CH, Nagaraja HN, Lau YL, Lau CS, Yu CY. Effects of Complement C4 Gene Copy Number Variations, Size Dichotomy, and C4A Deficiency on Genetic Risk and Clinical Presentation of Systemic Lupus Erythematosus in East Asian Populations Arthritis Rheumatol. 2016 Jun; 68(6): 1442-1453. 